\title{
COD removal from sucrose solution using hydrodynamic cavitation and hydrogen peroxide: a comparison between Venturi device and orifice plate
}

\section{Remoção de DQO de uma solução de sacarose usando cavitação hidrodinâmica e peróxido de hidrogênio: comparação entre Venturi e placa de orifício}

\author{
Paulo Henrique Lopes Alves ${ }^{1}$, Pedro de Souza Lopes Silva ${ }^{1}$, Deusmaque Carneiro Ferreira ${ }^{1}$ \\ and Julio Cesar de Souza Inácio Gonçalves ${ }^{1}$ \\ ${ }^{1}$ Universidade Federal do Triângulo Mineiro, Uberaba, MG, Brasil \\ E-mails: pauloh@facthus.edu.br(PHLA),pedro.s.ls@hotmail.com (PSLS), deusmaque.ferreira@uftm.edu.br (DCF), \\ julio.goncalves@uftm.edu.br (JCSIG)
}

Received: August 24, 2018 - Revised: October 24, 2018 - Accepted: December 29, 2018

\begin{abstract}
The aim of the current study is to compare the chemical oxygen demand (COD) removal efficiency of a Venturi device to that of an orifice plate. The inlet pressure in the devices was optimized and the degradation kinetics was analyzed. In addition, the synergistic effect resulting from the combination between cavitation and $\mathrm{H}_{2} \mathrm{O}_{2}$ was investigated. An experimental apparatus was built to achieve these goals. A sucrose solution and an effluent from a sucrose-based soft drink industry were treated. Results showed that the Venturi device recorded 90\% COD removal efficiency after three treatment minutes. On the other hand, the orifice plate recorded $90 \%$ COD removal efficiency after 9 min. The degradation kinetics-reaction order was 3.5, except for the highest Venturi inlet pressure (7.3 bar), which led to coalescence of cavities and to reduced degradation rate. The synergistic coefficient (Sc) was 185.20 and showed that the hybrid process $\left(\mathrm{HC}+\mathrm{H}_{2} \mathrm{O}_{2}\right)$ was much more efficient than the cavitation process applied alone. The high COD concentration in the effluent generated by the soft drink industry $\left(2,512.8 \mathrm{mg} \mathrm{L}^{-1}\right)$ was significantly decreased by $72 \%$. The combined use of cavitation and Venturi has significant potential to remove high organic matter concentrations in short treatment periods.
\end{abstract}

Keywords: Synergistic effect; Degradation; Hydroxyl radical; Kinetic coefficient; Microbubbles; Cavitation chamber.

\section{RESUMO}

O objetivo deste estudo foi comparar a eficiência de remoção de DQO de um Venturi e de uma placa de orifício. Adicionalmente, a otimização da pressão de entrada dos dispositivos, o estudo da cinética da degradação, e o efeito sinérgico resultante da combinação da cavitação e $\mathrm{H}_{2} \mathrm{O}_{2}$ foram realizados. Um aparato experimental em escala laboratorial foi construído para atingir esses objetivos. Uma solução de sacarose e um efluente real de uma indústria de refrigerante, a base de sacarose, foram tratados. Os resultados mostraram que o Venturi atingiu 90\% de remoção de DQO em apenas em três minutos de tratamento, com a pressão de 4,0 bar e proporção molar de sacarose: peróxido de 1:20. Enquanto que, para placa de orifício, uma eficiência de 90\% foi atingida em 9 min, na pressão de 2,0 bar. A ordem de reação da cinética de degradação foi igual a 3,5, com exceção da maior pressão de entrada do Venturi (7,3 bar) na qual ocorreu coalescência das cavidades e a redução na velocidade de degradação. O coeficiente sinérgico (Sc) foi igual a 185,20, mostrando que o processo híbrido $\left(\mathrm{HC}+\mathrm{H}_{2} \mathrm{O}_{2}\right)$ é muito mais eficiente do que a cavitação isolada. A elevada concentração de DQO do efluente da indústria de refrigerante $\left(2.512,8 \mathrm{mg} \mathrm{L}^{-1}\right)$ foi degradada no Venturi com eficiência de $72 \%$, sob uma pressão de entrada de 4,0 bar e baixa proporção (sacarose: peróxido de 1:10). O sistema de cavitação com dispositivo Venturi tem grande potencial para remover elevadas concentrações de matéria orgânica em um curto período de tratamento.

Palavras-chave: Efeito sinérgico; Degradação; Radical hidroxila; Coeficiente cinético; Microbolhas; Câmara de cavitação. 
COD removal from sucrose solution using hydrodynamic cavitation and hydrogen peroxide: a comparison between Venturi device and orifice plate

\section{INTRODUCTION}

Hydrodynamic cavitation is generated by liquids passing through physical constrictions such as orifice plates (HILARES et al., 2017), Venturi devices (CHOI et al., 2018) or partially closed valves (LI; SONG; YU, 2014). Microbubbles are generated when the pressure in the constriction falls below the vapor pressure of the liquid and they implode when the pressure of the liquid is recovered downstream of the constriction. Overall, hydrodynamic cavitation can be understood as the phenomenon encompassing the formation, growth and implosion (collapse) of vapor microbubbles (cavities) in a liquid medium (CAPOCELLI et al., 2014; RAJORIYA et al., 2018). This phenomenon happens within a short-time interval and releases substantial amounts of energy, which generate hot spots $(1,000$ to $10,000 \mathrm{~K})$ and high-pressure regions - from 10 to $500 \mathrm{MPa}$ (GOGATE; KABADI, 2009). Besides the physical changes, cavity collapse releases strong oxidants in the liquid medium (e.g., $\mathrm{OH}$ radicals) due to water molecule dissociation (GHAYAL; PANDIT; RATHOD, 2013; DULAR et al., 2016; RAJORIYA et al., 2018). In light of these characteristics, hydrodynamic cavitation has been used in different environmental engineering applications such as water supply and (KOSEL et al., 2017) wastewater (DULAR et al., 2016) treatments, as well as in algae removal from eutrophic lakes (BATISTA; ANHÊ; GONÇALVES, 2017).

Saharan et al. (2011) highlighted two major hydrodynamic cavitation mechanisms responsible for compound degradation: 1) decomposition/pyrolysis of organic molecules trapped within the cavities during collapse; and 2) reactions of $\mathrm{OH}$ radicals to pollutants at the cavity-water interface. In addition, the degradation efficiency of hydrodynamic cavitation reactors can improve through the use of oxidants such as $\mathrm{H}_{2} \mathrm{O}_{2}$ (SAHARAN et al., 2011), $\mathrm{CCl}_{4}$ (CHAKINALA et al., 2008) and $\mathrm{O}_{3}$ (ČEHOVIN et al., 2017). According to Raut-Jadhav et al. (2013), the combination between hydrodynamic cavitation and oxidants generates more reactive species, reduces mass transfer resistance and increases the turbulence generated during cavitation.

Many studies on hydrodynamic cavitation have been conducted in recent years to assess the cavitation potential to degrade specific organic compounds such as insecticides, dyes, endocrine disruptors, medicinal products, pesticides, among others (SAHARAN et al., 2011; RAUT-JADHAV et al., 2013; PATIL; BOTE; GOGATE, 2014; MUSMARRA et al., 2016; CHOI et al., 2018). Although cavitation is capable of degrading different compounds, it is essential conducting studies comparing the efficiency of cavitation-generating devices (or chambers), such as orifice plates and Venturi devices, to help optimizing and consolidating the hydrodynamic cavitation as wastewater treatment technique. Most studies driven by such goal are often based on computational simulations, which often present divergent results and require experimental corroboration (BASHIR et al., 2011; KULDEEP; SAHARAN 2016). According to Pawar et al. (2017), orifice plates provide the highest cavitation yield per dissipated energy unit due to the low density of produced microbubbles, whereas the cavitation yield of Venturi devices is affected by the high density of microbubbles, which interact with each other and generate less hydroxyl radicals during collapse. On the other hand, Kuldeep and Saharan (2016) stated that the Venturi device presents higher collapse intensity-related yield than orifice plates.
The present study compared the COD removal potential of a Venturi device to that of an orifice plate, under different inlet pressure conditions in the devices. The Venturi device and orifice plate dimensions were optimized in computational simulations, based on Bashir et al. (2011) and Kuldeep and Saharan (2016), respectively. The additional aims of the current study were:

- Optimizing the operating parameter 'inlet pressure of Venturi device';

- Defining the degradation kinetics order of the Venturi device by varying the inlet pressures;

- Finding the synergistic effect resulting from the combination between hydrodynamic cavitation (in the Venturi device at $4.0 \mathrm{bar}$ ) and hydrogen peroxide at molar ratio of sucrose: peroxide of 1:20;

- Estimating the degradation efficiency of an effluent generated by a soft drink industry by using the optimum inlet pressure found in the current study and the molar ratio of sucrose: peroxide of 1:10.

\section{MATERIAL AND METHODS}

\section{Materials}

The herein prepared sucrose solution (COD $953.76 \mathrm{mg} \mathrm{L}^{-1}$ ) was based on commercial sugar and tap water. Hydrogen peroxide $(30 \% \mathrm{w} / \mathrm{v})$ and sulfuric acid ( $97 \%$ P.A.) were used for solution oxidation and acidification purposes, respectively.

\section{Hydrodynamic cavitation device and analysis methods}

Figure 1 shows the schematic drawing of the experimental apparatus used in the current study. The system was built in closed circuit; it comprised a feed tank (8 L volume); a serial pumping system consisting of two pumps: a 1-hp "G1" peripheral pump (KSB®Hydrobloc, model P1000) and a 1.5-hp "G2” centrifugal pump (THEBE THA-16 Al); control valves "E"; digital pressure gauge "I"; wattmeter "F"; cavitation devices; pipes and connections.

Cavitation devices can be easily coupled to the apparatus by means of joints. The Venturi device dimensioning process was based on computational simulation performed by Bashir et al. (2011). The resulting Venturi device had rectangular throat (crosssectional area $=6.97 \times 10^{-6} \mathrm{~m}^{2}$ ), as well as convergent and divergent section dimensions (Figure 1). The orifice plate comprised a single orifice (3.0 × $10^{-3} \mathrm{~m}$ diameter; $9.0 \times 10^{-3} \mathrm{~m}$ thickness) and it was built based on the optimized geometric proportion suggested by Kuldeep and Saharan (2016).

The experimental temperatures were controlled through a heat exchanger composed of a copper tubing and a cold-water recirculating pump. The mean temperature was approximately $35^{\circ} \mathrm{C}$. The flow rate was controlled by the "E" valve and measured through a properly calibrated orifice plate "C" (flow coefficient $\mathrm{Cd}=0.70)$. The power consumed by the motor-pump system was measured in the wattmeter (PZEM-061, $1 \mathrm{~W}$ accuracy). The chemical oxygen demand (COD) was estimated through the closed-tube reflux colorimetric method by APHA (2012). 


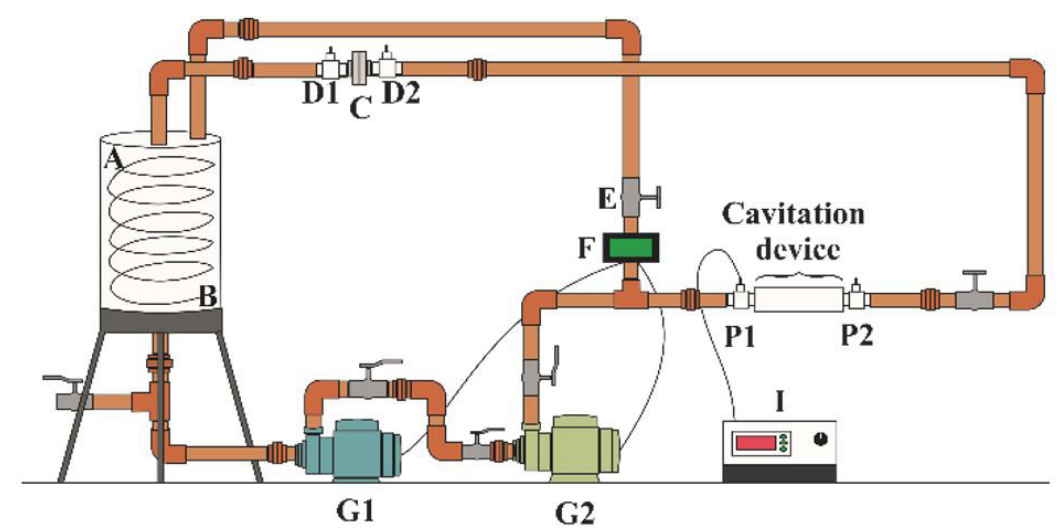

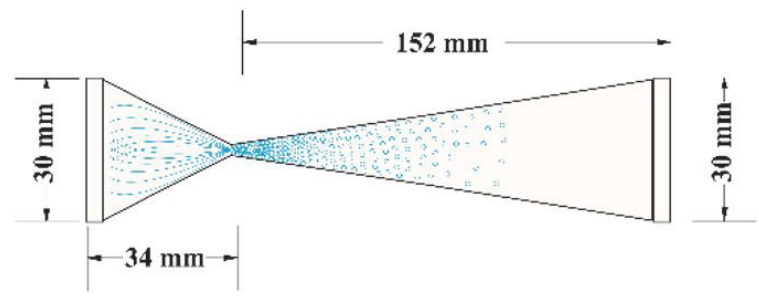

Venturi

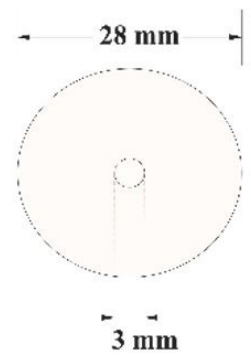

Orifice Plate

Figure 1. Schematic drawing of the experimental apparatus. P1 and P2 are the inlet and outlet pressures of the cavitation device; G1 and G2 are pumps in series; I is the digital manometer; F is the wattmeter; $C$ is the orifice plate for flow measurement; D1 and D2 are the pressure ports for flow measurement; $\mathrm{E}$ is the flow control valve; $\mathrm{A}$ and $\mathrm{B}$ are the inlet and outlet of the heat exchanger.

Table 1. Characteristics of the flow and power consumed in the cavitation devices.

\begin{tabular}{|c|c|c|c|c|c|c|c|c|}
\hline \multirow{2}{*}{ P1 (bar) $\rightarrow$} & \multicolumn{4}{|c|}{ Orifice plate } & \multicolumn{4}{|c|}{ Venturi } \\
\hline & 2.0 & 4.0 & 6.0 & 7.3 & 2.0 & 4.0 & 6.0 & 7.3 \\
\hline P2 (bar) & 0.050 & 0.091 & 0.125 & 0.143 & 0.059 & 0.063 & 0.067 & 0.069 \\
\hline Flow rate $\left(\mathrm{L} \mathrm{s}^{-1}\right)$ & 0.100 & 0.135 & 0.161 & 0.176 & 0.155 & 0.211 & 0.243 & 0.259 \\
\hline Velocity $\left(\mathrm{m} \mathrm{s}^{-1}\right)$ & 14.19 & 19.15 & 22.82 & 24.84 & 22.30 & 30.26 & 34.91 & 37.16 \\
\hline Cv (-) & 0.930 & 0.533 & 0.388 & 0.333 & 0.379 & 0.207 & 0.156 & 0.138 \\
\hline Power (W) & - & - & - & - & 1.998 & 1.989 & 1.978 & 1.983 \\
\hline
\end{tabular}

The COD removal performance of both cavitation devices was analyzed at four different inlet pressures (P1): 2.0, 4.0, 6.0 and 7.3 bar. According to Gagol, Przyjazny and Boczkaj (2018), P1 is one of the most important parameters adopted to evaluate hydrodynamic cavitation efficiency, since the higher the pressure the fluid enters the constriction, the larger the number of generated cavities.

The cavitation intensity was calculated based on the cavitation number $(\mathrm{Cv})$, represented in Equation 1:

$\mathrm{Cv}_{\mathrm{v}}=\frac{\left(\mathrm{P}_{2}-\mathrm{P}_{\mathrm{v}}\right)}{1 / 2 \rho \mathrm{V}_{0}^{2}}$

where: $\mathrm{Cv}$ is the cavitation number; $\mathrm{Pv}$ is the vapor pressure of the liquid $(\mathrm{Pa})$; $\varrho$ is the specific mass of the liquid $\left(\mathrm{kg} \mathrm{m}^{-3}\right)$; and $\mathrm{Vo}$ is flow rate in the Venturi throat $\left(\mathrm{m} \mathrm{s}^{-1}\right)$.

The $\mathrm{pH}$ of the sucrose solution was adjusted to 2.5 through sulfuric acid (P.A.) addition, before the treatment in the apparatus. This measure was adopted based on Mishra and Gogate (2010), Raut-Jadhav et al. (2013), Gogate and Bhosale (2013) and Gagol,
Przyjazny and Boczkaj (2018), who showed that the degradation of organic compounds was more efficient under acidic conditions. In addition, the molar ratio of sucrose: peroxide 1:20 was herein adopted. Raut-Jadhav et al. (2013) showed that optimal molar ratio of organic pollutant (Imidacloprid) to $\mathrm{H}_{2} \mathrm{O}_{2}$ required for effective degradation of organic pollutants is in the range of 1:10-1:60.

Table 1 shows the characteristics of the flow and the power consumed in the cavitation devices used in the current study.

The COD degradation kinetics was quantitatively expressed by Equation 2, in which the degradation rate depended on the product between the kinetic coefficient $(K)$ and the COD concentration. The power to which the concentration is raised is referred to as the reaction order.

$$
\frac{\mathrm{dCOD}}{\mathrm{dt}}=-\mathrm{KCOD}^{\mathrm{n}}
$$

The kinetic coefficient and reaction order estimates were based on the differential method by Chapra (2008). 
COD removal from sucrose solution using hydrodynamic cavitation and hydrogen peroxide: a comparison between Venturi device and orifice plate

The energy efficiency presented by the cavitation system based on different inlet pressures was estimated through the parameter $\mathrm{E}_{\mathrm{EO}}$ (Equation 3), defined by Bolton et al. (2001). This parameter quantifies the electrical energy $(\mathrm{kWh})$ per order for the estimation of the process feasibility. The higher the $\mathrm{E}_{\mathrm{EO}}$, the lower the pollutant removal efficiency in terms of electric power consumption.

$$
\mathrm{E}_{\mathrm{E} 0}=\frac{\mathrm{P} \mathrm{t} 1000}{\mathrm{~V} \log \left(\frac{\mathrm{CODi}}{\mathrm{CODf}}\right)}
$$

where: $\mathrm{P}$ is the power required by the system $(\mathrm{kW}) ; \mathrm{V}$ is the pollutant volume to be treated $(\mathrm{L})$; $\mathrm{t}$ is treatment time $(\mathrm{h})$; CODi and CODf are the initial and final pollutant concentrations $\left(\mathrm{g} \mathrm{L}^{-1}\right)$; and 1000 is the conversion factor.

\section{RESULTS AND DISCUSSION}

\section{The COD removal efficiency of the orifice plate and Venturi devices}

Figure 2 shows the COD removal percentage results recorded for the orifice plate and Venturi devices. The removal efficiency in the 15-minute treatment was approximately $90 \%$, except for pressure $7.3 \mathrm{bar}$ in the orifice plate. However, when the removal efficiency was analyzed at other treatment times $(3,6,9,12 \mathrm{~min})$, it was possible seeing that the Venturi device was more efficient than the orifice plate at all analyzed pressures. In addition, the Venturi device recorded high COD removal (90\%) after 3 treatment minutes, mainly at pressures 4.0 and 6.0 bar. On the other hand, the orifice plate reached $90 \%$ removal efficiency only after 9 treatment minutes at 2.0 bar. Consequently, the Venturi device presented better performance than the orifice plate, since it consumed less energy (shorter treatment time) to achieve removal efficiency close to $90 \%$.

The best performance of the Venturi device in comparison to that of the orifice plate can be explained through computational

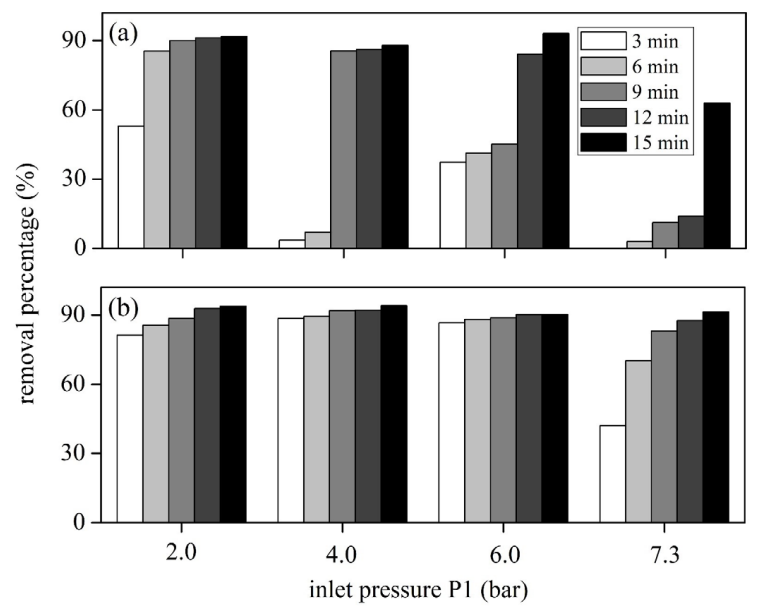

Figure 2. COD removal percentage at different treatment times and inlet pressures in the orifice plate (a) and in the Venturi device (b). Molar ratio of sucrose: peroxide 1:20, at $\mathrm{pH} 2.5$. simulation results presented by Kuldeep and Saharan (2016). According to them, in the orifice plate, the cavities (microbubbles) are generated at the inlet, and implode at the outlet, of the orifice. This process produces smaller cavities (since they did not have enough space to grow) and low collapse intensity (lower generation of hydroxyl radicals). On the other hand, the cavities in the venturi device are produced at the throat inlet and extend towards the divergent section, where they increase. There is high collapse intensity and higher generation of hydroxyl radicals when these cavities implode.

Another aspect that may have contributed to the higher Venturi device efficiency lies on the low values recorded for the cavitation number of this device (0.379 to 0.138 ) in comparison to the ones recorded for the orifice plate (0.933 to 0.333 ); the lower the $\mathrm{Cv}$ value, the higher the cavitation intensity. In addition, according to Kuldeep and Saharan (2016), the optimal Cv for wastewater treatments ranged from 0.15 to 0.25 . This range was reached by the Venturi device when P1 was equal to 4.0 and 6.0 bar. However, the orifice plate did not reach the optimum Cv range.

\section{Degradation kinetics of the Venturi device}

Figure 3 shows the COD decays (in percentage) recorded for different venturi inlet pressures. It is possible noticing that the Equation 2 well-fitted the experimental data ( $r^{2}$ higher than 0.988$)$. The degradation order was equal to 3.5 at pressures 2.0, 4.0 and 6.0 bar; 4.0 bar was the optimum pressure, since it allowed the kinetic coefficient $(K)$ and the removal efficiency $(R)$ to reach the highest values, $\mathrm{K}=2.5 \times 10^{-4} \mathrm{~L}^{2.5} \mathrm{mg}^{-2.5} \mathrm{~min}^{-1}$ and $\mathrm{R}=94 \%$, respectively. The degradation order at 7.3 bar was 1.0; this result indicated that the increased cavitation intensity (P1 increase) changed the COD removal mechanism, since the kinetics of the order 3.5 could not be used to describe the COD decay at all Venturi inlet pressures.

The reduced degradation order can be explained by the excess of cavities (vapor cloud formation) often generated at high P1 values such as 7.3 bar. According to Capocelli et al. (2014), the excess of cavitation in cavitation devices decreases the degradation rate due to the following reasons: 1-) increased likelihood of coalescence between cavities and reduced collapse intensity due to damping of the energy released at the implosion; and 2-) larger cavities resulting from coalescence escape the liquid without collapsing. This result was also recorded by Raut-Jadhav et al. (2013), Gogate and Bhosale (2013), Rajoriya et al. (2018) and Choi et al. (2018), who observed that the cavity cloud formation reduced the imidacloprid (neonicotinoid class of insecticide), orange acid-II (OA-II), textile effluent, and bisphenol A removal efficiency, respectively.

$\mathrm{E}_{\mathrm{EO}}$ showed similar behavior at pressures 2.0, 4.0 and $6.0 \mathrm{bar}$, in which the electrical energy per order increased over time. It indicated that the energy efficiency decreased as the experimental time increased. $\mathrm{E}_{\mathrm{EO}}$ did not have the same behavior at 7.3 bar, since it showed slight variation over time. Another important aspect to be highlighted is that the lowest mean $\mathrm{E}_{\mathrm{EO}}\left(33.71 \mathrm{kWh} \mathrm{m}^{-3}\right)$ was recorded at $4.0 \mathrm{bar}$, fact that confirmed this pressure value as the optimum operating parameter, since it was the pressure enabling the highest degradation rate (the highest kinetic coefficient) and the lowest $\mathrm{E}_{\mathrm{EO}}$. On the other hand, the worst performance was 


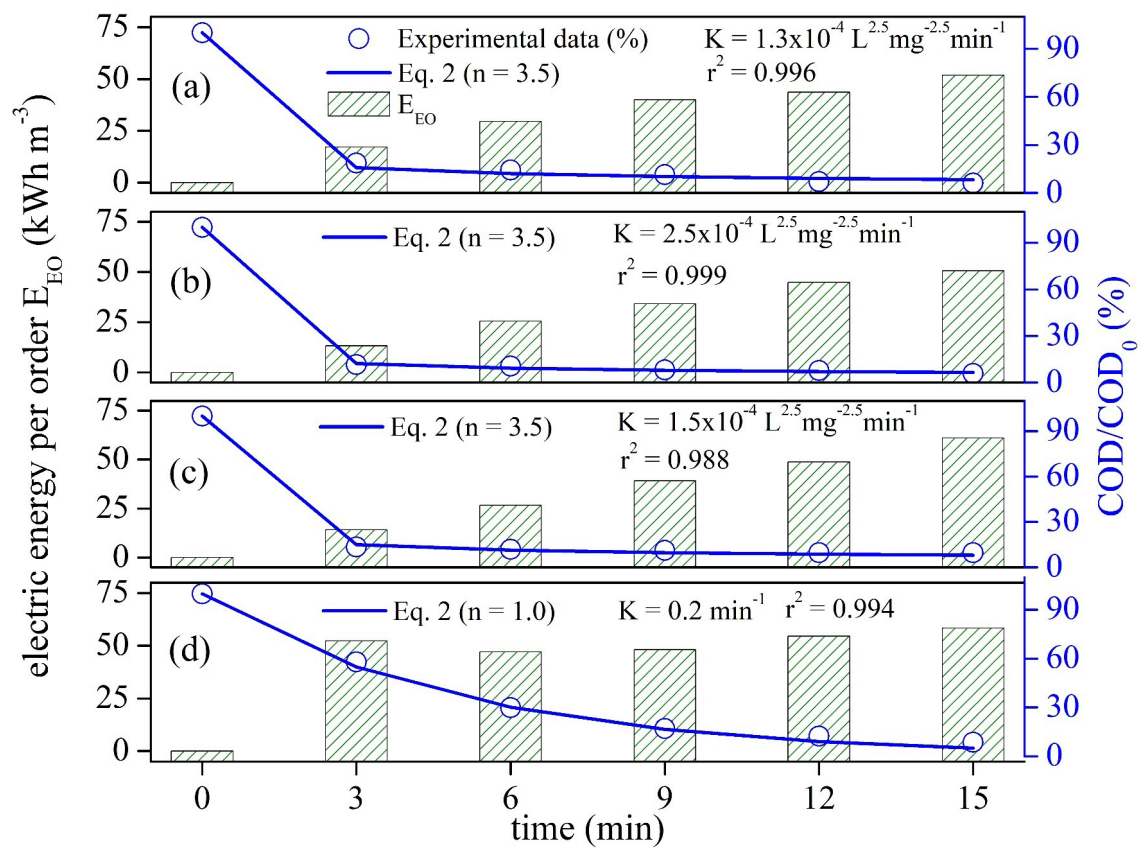

Figure 3. Degradation kinetics (in percentage) at different Venturi inlet pressures: (a) 2.0 bar; (b) 4.0 bar; (c) 6.0 bar; and (d) 7.3 bar; as well as the $\mathrm{E}_{\mathrm{EO}}$. Molar ratio of sucrose: peroxide 1:20, $\mathrm{pH} 2.5$.

recorded at 7.3 bar, since it enabled the lowest reaction order and the highest mean $\mathrm{E}_{\mathrm{EO}}\left(46.49 \mathrm{kWh} \mathrm{m}^{-3}\right)$.

\section{Analyzing the synergistic effect between hydrodynamic cavitation and hydrogen peroxide}

The hydrogen peroxide-free experiments were carried out in the Venturi device at 4.0 bar, whereas the experiment with hydrogen peroxide alone, at molar ratio of sucrose: peroxide of $1: 20$, was conducted in a magnetic stirrer at low speed (100 rpm). Thus, it was possible evaluating the removal rate by taking into consideration the hydrodynamic cavitation (HC) and the hydrogen peroxide $\left(\mathrm{H}_{2} \mathrm{O}_{2}\right)$, in separate. Figure 4 shows the isolated effects of these processes.

Based on Figure 4, the reaction order in both processes can be expressed as $\mathrm{n}=3.5$ and cavitation (alone) was more effective in removing COD than hydrogen peroxide (alone) in a low-mix reactor. The hydrodynamic cavitation showed $50.9 \%$ removal efficiency after 15 treatment minutes, whereas the hydrogen peroxide recorded $5.5 \%$.

The kinetic coefficient $(\mathrm{K})$ values for $\mathrm{HC}, \mathrm{H}_{2} \mathrm{O}_{2}$, and $\mathrm{HC}$ $+\mathrm{H}_{2} \mathrm{O}_{2}$ (Figure $3 \mathrm{~b}$ ) showed substantial synergistic effect, since $\mathrm{K}$ increased from $5.0 \times 10^{-8} \mathrm{~L}^{2.5} \mathrm{mg}^{-2.5} \mathrm{~min}^{-1}$ (when peroxide was used without cavitation) to $2.5 \times 10^{-4} \mathrm{~L}^{2.5} \mathrm{mg}^{-2.5} \mathrm{~min}^{-1}$ (when peroxide was used with hydrodynamic cavitation). This synergistic effect can be quantified through the synergistic coefficient $(\mathrm{Sc})$ presented in Equation 4, as suggested by Raut-Jadhav et al. (2013):

$\mathrm{Sc}=\frac{\mathrm{K}_{\left(\mathrm{HC}+\mathrm{H}_{2} \mathrm{O}_{2}\right)}}{\mathrm{K}_{\mathrm{HC}}+\mathrm{K}_{\mathrm{H}_{2} \mathrm{O}_{2}}}$

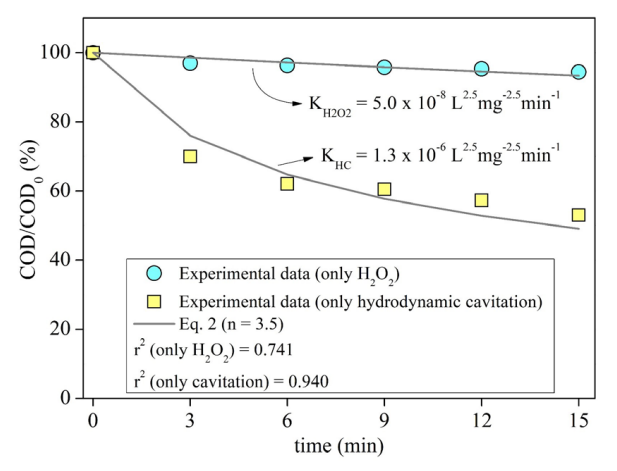

Figure 4. Comparison between degradation kinetics (in percentage) in two experiments: one performed in a magnetic stirrer at molar ratio of sucrose: peroxide 1:20, $\mathrm{pH} 2.5$; and the other one performed in the cavitation system (Venturi device; P1 4.0 bar) without $\mathrm{H}_{2} \mathrm{O}_{2}$, at $\mathrm{pH} 2.5$.

where: $\mathrm{K}_{\left(\mathrm{HC}+\mathrm{H}_{2} \mathrm{O}_{2}\right)}$ is the kinetic coefficient for the cavitation-peroxide combination (P1 4.0 bar; $\mathrm{pH} 2.5$; and molar ratio of sucrose: $\left.\mathrm{H}_{2} \mathrm{O}_{2} 1: 20\right) ; \mathrm{K}_{\mathrm{HC}}$ is the kinetic coefficient for the peroxide-free cavitation ( $\mathrm{P} 14.0$ bar; and $\mathrm{pH}$ 2.5); and $\mathrm{K}_{\mathrm{H}_{2} \mathrm{O}_{2}}$ is the kinetic coefficient for the cavitation-free peroxide $(\mathrm{pH} 2.5$; molar ratio of sucrose: $\mathrm{H}_{2} \mathrm{O}_{2}$ 1:20).

The synergistic coefficient value recorded in the current study was 185.20. The high Sc value can be explained by the fact that the hydrodynamic cavitation increased the $\mathrm{H}_{2} \mathrm{O}_{2}$ dissociation rate and, consequently, increased the generation of hydroxyl radicals, as shown in Equation 5. According to Raut-Jadhav et al. (2013), the hydrodynamic cavitation also increased the effective 


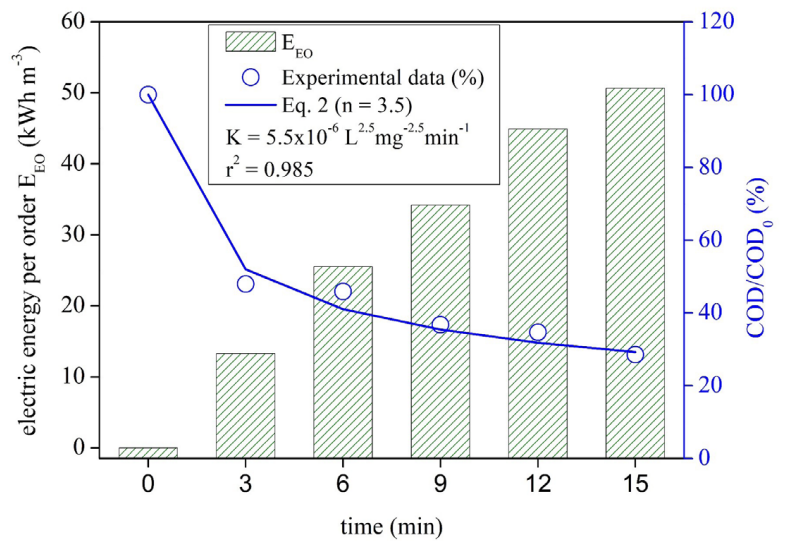

Figure 5. Degradation kinetics of the effluent generated by the soft drink industry and electric power consumed for COD removal by the order of magnitude of one volume unit. P1 4.0bar (Venturi device). Molar ratio of sucrose: peroxide 1:10; pH 2.5.

use of hydroxyl radicals by pollutant molecules, since it increased the micro mixture and, consequently, increased the mass transfer between molecules in the system.

$\mathrm{H}_{2} \mathrm{O}_{2} \quad \overrightarrow{\text { cavitation }} \mathrm{OH}+\mathrm{OH}^{\cdot}$

\section{COD removal from an effluent generated by a soft drink industry}

Although many studies have investigated the hydrodynamic cavitation efficiency in removing synthetic pollutants (PARSA; ZONOUZIAN, 2013; MUSMARRA et al., 2016; CHOI et al., 2018), few studies investigated the use of actual effluents with high COD concentration, so far. According to Rajoriya et al. (2018), it is necessary testing the actual effluent before the hydrodynamic cavitation application on an industrial scale. Therefore, the current study made the option for testing the optimal sucrose solution degradation efficiency parameters by treating a sucrose-based effluent generated by a soft drink industry.

The effluent was collected in the aforementioned industry, which generates $0.8 \mathrm{~m}^{3} \mathrm{~d}^{-1}$ flow rate at COD concentration $2,512.8 \mathrm{mg} \mathrm{L}^{-1}$. It was treated in the cavitation system at $\mathrm{P} 1=4.0 \mathrm{bar}$ (Venturi device), pH 2.5 and molar ratio of sucrose: peroxide 1:10. Figure 5 shows the degradation kinetics and consumed energy results. The degradation kinetics recorded for the effluent generated by the soft drink industry was in the order of 3.5; this result corroborates the ones recorded for the sucrose solution. The $\mathrm{E}_{\mathrm{EO}}$ showed equivalent results. Based on Figure $3 \mathrm{~b}$, the energy efficiency of the system decreased - since the $\mathrm{E}_{\mathrm{EO}}$ increased over time - and reached $50 \mathrm{kWh} \mathrm{m}^{-3}$, after 15 treatment minutes.

The COD removal efficiency reached $72 \%$ after 15 treatment minutes. This value was high, since the hydrogen peroxide proportion reduced by $50 \%$ in comparison to the sucrose solution proportion (1:20). Despite the reduced hydrogen peroxide proportion, the COD removal efficiency decreased only by $22 \%$. Based on this result, the removal efficiency did not show linear dependence on hydrogen peroxide addition, as shown in studies by Raut-Jadhav et al. (2013), Gogate and Bhosale (2013) and Dular et al. (2016).

\section{CONCLUSIONS}

The present study investigated the hydrodynamic cavitation efficiency in removing COD from sucrose solution and from an effluent generated by a soft drink industry. Experiments were conducted in an experimental closed-circuit apparatus, in which the cavitation phenomenon was generated by two devices: Venturi or orifice plate. The results of the experiments showed that:

- The Venturi device showed higher COD removal efficiency than the orifice plate at all analyzed pressures;

- The maximum removal efficiency recorded $94 \%$ at inlet pressure 4.0 bar in the Venturi device;

- The degradation kinetics of the synthetic effluent, and of the effluent generated by the soft drink industry, was in the order of 3.5 ;

- The COD degradation rate decreased due to the cavity coalescence phenomenon, which reduced the collapse intensity and the hydroxyl radical production. This phenomenon happened when the inlet pressure reached 7.3 bar;

- The energy efficiency decreased as the treatment time increased. The inlet pressure 4.0 bar was the one presenting the best energy performance, since this pressure enabled the lowest mean $\mathrm{E}_{\mathrm{EO}}$ value;

- The high synergistic coefficient value (Sc 185.20) recorded in the current study showed that the hybrid process (hydrodynamic cavitation + hydrogen peroxide) was much more efficient in removing COD than the processes applied alone;

- The high COD concentration in the effluent generated by the soft drink industry was significantly decreased by $72 \%$ under optimum hydrodynamic condition in the Venturi device (P1 4.0 bar), at low molar ratio of sucrose: peroxide 1:10. This result showed that the cavitation system can be used to remove high organic matter loads in a short period of time (15 min), at low $\mathrm{H}_{2} \mathrm{O}_{2}$ concentrations.

\section{REFERENCES}

AMERICAN PUBLIC HEALTH ASSOCIATION - APHA. Standard methods for examination of water and wastewater. 22nd ed. Washington: APHA, 2012. 1360 p.

BASHIR, T. A.; SONI, A. G.; MAHULKAR, A. V.; PANDIT, A. B. The CFD driven optimisation of a modified venturi for cavitational activity. Canadian Journal of Chemical Engineering, v. 89, n. 6, p. 1366-1375, 2011. http://dx.doi.org/10.1002/cjce.20500.

BATISTA, M. D.; ANHÊ, A. C. B. M.; GONÇALVES, J. C. S. I. Use of hydrodynamic cavitation for Algae Removal: effect on the 
inactivation of microalgae belonging to genus Scenedesmus. Water, Air, and Soil Pollution, v. 228, n. 11, p. 443, 2017. http://dx.doi. org/10.1007/s11270-017-3624-x.

BOLTON, J. R.; BIRCHER, K. G.; TUMAS, W.; TOLMAN, C. A. Figures-of-merit for the technical development of advanced oxidation technologies for both electric and solar driven system. Pure and Applied Chemistry, v. 73, n. 4, p. 627-637, 2001. http:// dx.doi.org/10.1351/pac200173040627.

CAPOCELLI, M.; PRISCIANDARO, M.; LANCIA, A.; MUSMARRA, D. Hydrodynamic cavitation of p-nitrophenol: A theoretical and experimental insight. Chemical Engineering Journal, v. 254, p. 1-8, 2014. http://dx.doi.org/10.1016/j.cej.2014.05.102.

ČEHOVIN, M.; MEDIC, A.; SCHEIDELER, J.; MIELCKE, J.; RIED, A.; KOMPARE, B.; ŽGAJNAR GOTVAJN, A. Hydrodynamic cavitation in combination with the ozone, hydrogen peroxide and the UV-based advanced oxidation processes for the removal of natural organic matter from drinking water. Ultrasonics Sonochemistry, v. 37, p. 394-404, 2017. http://dx.doi.org/10.1016/j. ultsonch.2017.01.036. PMid:28427649.

CHAKINALA, A. G.; GOGATE, P. R.; CHAND, R.; BREMNER, D. H.; MOLINA, R.; BURGESS, A. E. Intensification of oxidation capacity using chloroalkanes as additives in hydrodynamic and acoustic cavitation reactors. Ultrasonics Sonochemistry, v. 15, n. 3, p. 164-170, 2008. http://dx.doi.org/10.1016/j.ultsonch.2007.02.008. PMid:17481935.

CHAPRA, S. C. Surface water-quality modeling. Long Grove: Waveland, 2008. 844 p.

CHOI, J.; CUI, M.; LEE, Y.; KIM, J.; SON, Y.; KHIM, J. Hydrodynamic cavitation and activated persulfate oxidation for degradation of bisphenol A: kinetics and mechanism. Chemical Engineering Journal, v. 338, p. 323-332, 2018. http://dx.doi.org/10.1016/j.cej.2018.01.018.

DULAR, M.; GRIESSLER-BULC, T.; GUTIERREZ-AGUIRRE, I.; HEATH, E.; KOSJEK, T.; KRIVOGRAD KLEMENČIČ, A.; ODER, M.; PETKOVŠEK, M.; RAČKI, N.; RAVNIKAR, M.; ŠARC, A.; ŠIROK, B.; ZUPANC, M.; ŽITNIK, M.; KOMPARE, B. Ultrasonics sonochemistry use of hydrodynamic cavitation in (waste) water treatment. Ultrasonics Sonochemistry, v. 29, p. $577-$ 588, 2016. http://dx.doi.org/10.1016/j.ultsonch.2015.10.010. PMid:26515938.

GA_GOL, M.; PRZYJAZNY, A.; BOCZKAJ, G. Wastewater treatment by means of advanced oxidation processes based on cavitation: a review. Chemical Engineering Journal, v. 338, p. 599-627, 2018. http://dx.doi.org/10.1016/j.cej.2018.01.049.

GHAYAL, D.; PANDIT, A. B.; RATHOD, V. K. Optimization of biodiesel production in a hydrodynamic cavitation reactor using used frying oil. Ultrasonics Sonochemistry, v. 20, n. 1, p. 322-328, 2013. http://dx.doi.org/10.1016/j.ultsonch.2012.07.009. PMid:22922070.
GOGATE, P. R.; BHOSALE, G. S. Comparison of effectiveness of acoustic and hydrodynamic cavitation in combined treatment schemes for degradation of dye wastewaters. Chemical Engineering and Processing: Process Intensification, v. 71, p. 59-69, 2013. http:// dx.doi.org/10.1016/j.cep.2013.03.001.

GOGATE, P. R.; KABADI, A. M. A review of applications of cavitation in biochemical engineering/biotechnology. Biochemical Engineering Journal, v. 44, n. 1, p. 60-72, 2009. http://dx.doi. org/10.1016/j.bej.2008.10.006.

HILARES, R. T.; IENNY, J. V.; MARCELINO, P. F.; AHMED, M. A.; ANTUNES, F. A. F.; SILVA, S. S.; SANTOS, J. C. Ethanol production in a simultaneous saccharification and fermentation process with interconnected reactors employing hydrodynamic cavitation-pretreated sugarcane bagasse as raw material. Bioresource Technology, v. 243, p. 652-659, 2017. http://dx.doi.org/10.1016/j. biortech.2017.06.159. PMid:28709070.

KOSEL, J.; GUTIÉRREZ-AGUIRRE, I.; RAČKI, N.; DREO, T.; RAVNIKAR, M.; DULAR, M. Efficient inactivation of MS-2 virus in water by hydrodynamic cavitation. Water Research, v. 124, p. 465-471, 2017. http://dx.doi.org/10.1016/j.watres.2017.07.077. PMid:28800517.

KULDEEP; SAHARAN, V. K. Computational study of different venturi and orifice type hydrodynamic cavitating devices. Journal of Hydrodynamics, v. 28, n. 2, p. 293-305, 2016. http://dx.doi. org/10.1016/S1001-6058(16)60631-5.

LI, P.; SONG, Y.; YU, S. Removal of microcystis aeruginosa using hydrodynamic cavitation: performance and mechanisms. Water Research, v. 62, p. 241-248, 2014. http://dx.doi.org/10.1016/j. watres.2014.05.052. PMid:24960124.

MISHRA, K. P.; GOGATE, P. R. Intensification of degradation of Rhodamine B using hydrodynamic cavitation in the presence of additives. Separation and Purification Technology, v. 75, n. 3, p. 385-391, 2010. http://dx.doi.org/10.1016/j.seppur.2010.09.008.

MUSMARRA, D.; PRISCIANDARO, M.; CAPOCELLI, M.; KARATZA, D.; IOVINO, P.; CANZANO, S.; LANCIA, A. Degradation of ibuprofen by hydrodynamic cavitation: Reaction pathways and effect of operational parameters. Ultrasonics Sonochemistry, v. 29, p. 76-83, 2016. http://dx.doi.org/10.1016/j. ultsonch.2015.09.002. PMid:26584987.

PARSA, J. B.; ZONOUZIAN, A. S. E. Optimization of a heterogeneous catalytic hydrodynamic cavitation reactor performance in decolorization of Rhodamine B: application of scrap iron sheets. Ultrasonics Sonochemistry, v. 20, n. 6, p. 1442-1449, 2013. http:// dx.doi.org/10.1016/j.ultsonch.2013.04.013. PMid:23714332.

PATIL, P. N.; BOTE, S. D.; GOGATE, P. R. Degradation of imidacloprid using combined advanced oxidation processes based on hydrodynamic cavitation. Ultrasonics Sonochemistry, v. 21, n. 5, p. 1770-1777, 2014. http://dx.doi.org/10.1016/j.ultsonch.2014.02.024. PMid:24631443. 
COD removal from sucrose solution using hydrodynamic cavitation and hydrogen peroxide: a comparison between Venturi device and orifice plate

PAWAR, S. K.; MAHULKAR, A. V.; PANDIT, A. B.; ROY, K.; MOHOLKAR, V. S. Sonochemical effect induced by hydrodynamic cavitation: comparison of venturi/orifice flow geometries. $A I C h E$ Journal. American Institute of Chemical Engineers, v. 63, n. 10, p. 47054716, 2017. http://dx.doi.org/10.1002/aic.15812.

RAJORIYA, S.; BARGOLE, S.; GEORGE, S.; SAHARAN, V. K. Treatment of textile dyeing industry effluent using hydrodynamic cavitation in combination with advanced oxidation reagents. Journal of Hazardous Materials, v. 344, p. 1109-1115, 2018. http://dx.doi. org/10.1016/j.jhazmat.2017.12.005. PMid:30216970.

RAUT-JADHAV, S.; SAHARAN, V. K.; PINJARI, D.; SONAWANE, S.; SAINI, D.; PANDIT, A. Synergetic effect of combination of AOP's (hydrodynamic cavitation and $\mathrm{H} 2 \mathrm{O} 2$ ) on the degradation of neonicotinoid class of insecticide. Journal of Hazardous Materials, v. 261, p. 139-147, 2013. http://dx.doi.org/10.1016/j. jhazmat.2013.07.012. PMid:23912079.
SAHARAN, V. K.; BADVE, M. P.; PANDIT, A. B. Degradation of reactive red 120 dye using hydrodynamic cavitation. Chemical Engineering Journal, v. 178, p. 100-107, 2011. http://dx.doi. org/10.1016/j.cej.2011.10.018.

\section{Authors contributions}

Paulo Henrique Lopes Alves: Initial conception of the research; literature search; data collection; writing and formatting of the paper.

Pedro de Souza Lopes Silva: Review of previous work; writing and formatting of the paper; and discussion of the results.

Deusmaque Carneiro Ferreira: Review of previous work; writing and formatting of the paper and discussion of the results.

Julio Cesar de Souza Inácio Gonçalves: Advisor Professor; initial conception of the research; analysis of results and drafting the paper. 